\title{
The Effect Of The 1994 Redefinition Of The FORTUNE 500 On Its Usability As A Benchmark For Corporate Profitability
}

Andrew J. Deile (email: deile_aj@mercer.edu), Mercer University

\begin{abstract}
Virtually every Strategic Management casebook has an "advice on how to prepare cases" section. Within this section invariably is an admonition to "crunch some numbers" (e.g., ROE, ROA). A weakness of these advice sections is that they do not give good guidance to the student as to what to compare the "crunched numbers" to. This paper will argue that the FORTUNE 500 is an appropriate benchmark for evaluating corporate profitability. With 48 years (1954 to 2001) of data we are able to effectively place a given firm's profitability in perspective. One relatively major problem exists however. Prior to 1994, the FORTUNE 500 was really two separate 500'sthe traditional "manufacturing" 500 and the "service" 500. Beginning in 1994 FORTUNE combined these two lists. While this might not appear to be an overwhelming problem, an examination of the profitability components of the "Dupont" equation for the FORTUNE 500 reveals some substantial dissonance. This paper suggests a relatively minor adjustment that can be made to the recent (post '94) numbers such that we can have a relatively congruent 48 year data set that can be used as a benchmark for all corporations except "financial institutions."
\end{abstract}

\subsection{Introduction}

$T$ he typical Strategic Management/Business Policy casebook has an "advice on how to prepare cases" section. Within this section is invariably an admonition to "crunch some numbers" (e.g., ROE, ROA). For example, Thompson and Strickland suggest, "A big majority of strategy cases call for some kind of number crunching--calculating assorted financial ratios to check out the company's financial condition and recent performance...........see Table 1 on the next page for a summary of key financial ratios, how they are calculated, and what they show" (Thompson and Strickland, page C-5).

Turning to pages C-6 and C-7, the authors briefly discuss and explain 24 "Key Financial Ratios," and they suggest that the student compare them to either, Modern Industry and Dun's Reviews, Morris Associates' Annual Statement Studies, or the FTC-SEC's Quarterly Financial Report (Thompson and Strickland, pages C-6 \& C-7).

There are two major problems that exist with this advice. First, the student's efforts will result in a relatively limited number of year's data. Second, the comparisons will be with supposedly "like" firms. If all cases in Strategic Management/Business Policy casebooks had cases "up to yesterday" and were about firms that had other "truly like" firms to use for comparison these problems would not be as major as they are.

In the real world of university teaching some of the most useful cases to use for intellectual exercise for the student are those that describe "classic" situations that do not have data ending yesterday. Students will be hard pressed to find ratio "standards" for these cases from the above sources. Furthermore, while it can be argued that it is appropriate to compare the ratios or say, United Airlines to those for American Airlines and Delta Airlines, most

Readers with comments or questions are encouraged to contact the author via email. 
of the world is not that easy. For example, what is a good "like" firm to compare Philip Morris (Altria as of 1/27/03) with? There is none! Microsoft has no "like" firm, nor do Amazon.Com nor eBay, nor arguably most "interesting" firms.

This paper will argue that the FORTUNE 500 is an appropriate benchmark for evaluating corporate profitability. We have 48 years (1954 to 2001) of data to use (2002 data should be available about the time that this paper is presented), such that we are able to effectively place a given firm's profitability in proper perspective. In response to those who would say, "using the FORTUNE 500 as a comparison is too generic--it's like comparing a given firm's performance to economic conditions in general," I respond that that is the point! A glance at the FORTUNE 500 "Dupont" ratios will show that corporate profitability does vary with the state of the economy. So what if all of the firms in "Industry X" had ROAs above the FORTUNE 500 average--part of their top management's job is to decide the classic question of "what business are we in" and they came up with the correct answer. Likewise if all of the firms in "Industry Y" have ROAs below the FORTUNE 500 average, we can argue that their collective top management doesn't know the answer at the classic question of "what business are we in?"

\subsection{Brief History of the FORTUNE 500}

In July 1955 FORTUNE came out with what at the time was a rather innovative idea--rank all of the manufacturing firms in the United States by size and list the 500 largest--the elite of American business. Since then the term "FORTUNE 500 firm" has come to mean a firm that is to be taken seriously--one of the "movers and shakers" of the economy.

The first two 500 lists only gave Sales, Assets, and Profits for the firms. It was not until the 1956 data was published in July 1957 that FORTUNE decided to add listings for Shareholder's Equity. Thus only the first half of the "Dupont" equation can be computed for those years.

Gradually FORTUNE started appending lists of "non-manufacturing" firms to the "main" 500, until in the 1970's they came out with a separate "SERVICE 500." The "Dupont" numbers for some of the industries in the SERVICE 500 were radically different from the FORTUNE 500 especially for Total Asset Turnover and Leverage. But as long as the two 500's were published separately, the long term data comparisons that were valid for most companies were intact.

Then came 1995 and the publication of a combined FORTUNE 500 for 1994. The firms were still ranked by sales revenue, but now all firms--manufacturing and service--were on the same list. Suddenly the 41 year (to that point) data set was no longer valid.

\subsection{Making Sense of Recent FORTUNE 500s}

As the following table shows, the "Dupont" numbers change rather dramatically in 1994 . I will call this the "Pure" FORTUNE 500 because it uses the aggregate numbers without any adjustment. Clearly the compatibility within the database became "corrupted" in 1994.

One solution would be to reconstruct the 1994 to-date FORTUNE 500's in the old format. However, it would be difficult to ascertain if we had included the "correct" firms and it can be argued that the inclusion of Transportation, Retailing, Utility, and other diversified service firms makes the FORTUNE 500 a more useful basis for comparison. The incompatibility comes when we mix in the Banks, Insurance Companies and other Financial Institutions. These firms have Income Statements and Balance Sheets that differ markedly from the rest of the corporate world. 
TABLE 1--"Pure" FORTUNE 500 Dupont Ratios

$\begin{array}{llllll}\text { YEAR } & \mathbf{R O S} & \mathbf{S} / \mathbf{A} & \mathbf{R O A} & \mathbf{A} / \mathbf{E} & \mathbf{R O E} \\ 1954 & 6.04 & 1.27 & 7.66 & -- & -- \\ 1955 & 6.95 & 1.32 & 9.17 & -- & - \\ 1956 & 6.60 & 1.25 & 8.28 & 1.59 & 13.14 \\ 1957 & 6.19 & 1.27 & 7.83 & 1.57 & 12.27 \\ 1958 & 5.42 & 1.15 & 6.21 & 1.53 & 9.51 \\ 1959 & 6.07 & 1.17 & 7.11 & 1.55 & 11.00 \\ 1960 & 5.68 & 1.16 & 6.60 & 1.53 & 10.09 \\ 1961 & 5.55 & 1.12 & 6.22 & 1.54 & 9.59 \\ 1962 & 5.89 & 1.16 & 6.84 & 1.55 & 10.59 \\ 1963 & 6.05 & 1.17 & 7.11 & 1.56 & 11.10 \\ 1964 & 6.47 & 1.19 & 7.67 & 1.58 & 12.11 \\ 1965 & 6.71 & 1.18 & 7.95 & 1.63 & 12.99 \\ 1966 & 6.64 & 1.18 & 7.83 & 1.69 & 13.24 \\ 1967 & 5.96 & 1.13 & 6.75 & 1.74 & 11.76 \\ 1968 & 5.97 & 1.12 & 6.70 & 1.82 & 12.19 \\ 1969 & 5.55 & 1.10 & 6.15 & 1.87 & 11.49 \\ 1970 & 4.67 & 1.07 & 5.01 & 1.90 & 9.54 \\ 1971 & 4.66 & 1.10 & 5.14 & 1.90 & 9.76 \\ 1972 & 4.99 & 1.15 & 5.73 & 1.90 & 10.90 \\ 1973 & 5.80 & 1.20 & 6.96 & 1.96 & 13.68 \\ 1974 & 5.23 & 1.33 & 6.94 & 2.03 & 14.09 \\ 1975 & 4.37 & 1.29 & 5.66 & 2.02 & 11.42 \\ 1976 & 5.06 & 1.32 & 6.70 & 2.01 & 13.49 \\ 1977 & 4.84 & 1.35 & 6.54 & 2.04 & 13.31 \\ 1978 & 5.05 & 1.36 & 6.85 & 2.08 & 14.22 \\ 1979 & 5.41 & 1.40 & 7.55 & 2.14 & 16.12 \\ 1980 & 4.92 & 1.40 & 6.91 & 2.17 & 15.00 \\ 1981 & 4.75 & 1.38 & 6.57 & 2.18 & 14.34 \\ 1982 & 3.67 & 1.28 & 4.69 & 2.18 & 10.23 \\ 1983 & 4.08 & 1.25 & 5.08 & 2.14 & 10.89 \\ 1984 & 4.91 & 1.25 & 6.13 & 2.21 & 13.57 \\ 1985 & 3.85 & 1.19 & 4.58 & 2.27 & 10.40 \\ 1986 & 3.77 & 1.10 & 4.16 & 2.42 & 10.07 \\ 1987 & 4.82 & 1.10 & 5.31 & 2.49 & 13.22 \\ 1988 & 5.68 & 0.97 & 5.53 & 2.98 & 16.47 \\ 1989 & 4.88 & 0.95 & 4.61 & 3.18 & 14.68 \\ 1990 & 4.05 & 0.95 & 3.86 & 3.25 & 12.54 \\ 1991 & 2.44 & 0.92 & 2.24 & 3.22 & 7.22 \\ 1992 & 2.98 & 0.93 & 2.76 & 3.61 & 9.97 \\ 1993 & 3.45 & 0.89 & 3.05 & 3.69 & 11.26 \\ 1994 & 5.04 & 0.45 & 2.25 & 6.40 & 14.41 \\ 1995 & 5.20 & 0.45 & 2.33 & 6.29 & 14.62 \\ 1996 & 5.93 & 0.44 & 2.61 & 6.17 & 16.07 \\ 1997 & 5.88 & 0.43 & 2.52 & 6.20 & 15.62 \\ 1998 & 5.82 & 0.40 & 2.34 & 6.39 & 14.96 \\ 1999 & 6.48 & 0.39 & 2.56 & 6.40 & 16.36 \\ 2000 & 6.18 & 0.41 & 2.51 & 6.09 & 15.28 \\ 2001 & 2.78 & 0.39 & 1.08 & 6.11 & 6.61\end{array}$

A more reasonable solution is to eliminate the above mentioned Financial Institutions. Using the 2001 data as an example we are left with what is technically a "FORTUNE 417" (83 firms removed). I will call this the "Adjusted" FORTUNE 500. The table below includes new columns for the last 8 years, listed ADJ. ROS, ADJ. S/A, etc. 
TABLE 2--"Pure" and "Adjusted" FORTUNE 500 Dupont Ratios

\begin{tabular}{|c|c|c|c|c|c|c|c|c|c|c|}
\hline YEAR & $\begin{array}{l}\text { PURE } \\
\text { ROS }\end{array}$ & $\begin{array}{l}\text { ADJ. } \\
\text { ROS }\end{array}$ & $\begin{array}{l}\text { PURE } \\
\text { S/A }\end{array}$ & $\begin{array}{l}\text { ADJ. } \\
\text { S/A }\end{array}$ & $\begin{array}{l}\text { PURE } \\
\text { ROA }\end{array}$ & $\begin{array}{l}\text { ADJ. } \\
\text { ROA }\end{array}$ & $\begin{array}{l}\text { PURE } \\
\text { A/E }\end{array}$ & $\begin{array}{l}\text { ADJ. } \\
\text { A/E }\end{array}$ & $\begin{array}{l}\text { PURE } \\
\text { ROE }\end{array}$ & $\begin{array}{l}\text { ADJ. } \\
\text { ROE }\end{array}$ \\
\hline $\begin{array}{l}1954 \\
1955\end{array}$ & $\begin{array}{l}6.04 \\
6.95\end{array}$ & $\begin{array}{l}6.04 \\
6.95\end{array}$ & $\begin{array}{l}1.27 \\
1.32\end{array}$ & $\begin{array}{l}1.27 \\
1.32\end{array}$ & $\begin{array}{l}7.66 \\
9.17\end{array}$ & $\begin{array}{l}7.66 \\
9.17\end{array}$ & $\begin{array}{l}-- \\
--\end{array}$ & & $\begin{array}{l}-- \\
--\end{array}$ & \\
\hline 1956 & 6.60 & 6.60 & 1.25 & 1.25 & 8.28 & 8.28 & 1.59 & 1.59 & 13.14 & 13.14 \\
\hline 1957 & 6.19 & 6.19 & 1.27 & 1.27 & 7.83 & 7.83 & 1.57 & 1.57 & 12.27 & \\
\hline 1958 & 5.42 & 5.42 & 1.15 & 1.15 & 6.21 & 6.21 & 1.53 & 1.53 & 9.51 & 9.5 \\
\hline 1959 & 6.07 & 6.07 & 1.17 & 1.17 & 7.11 & 7.11 & 1.55 & 1.55 & 11.00 & 11.00 \\
\hline 1960 & 5.68 & 5.68 & 1.16 & 1.16 & 6.60 & 6.60 & 1.53 & 1.53 & 10.09 & \\
\hline 1961 & 5.55 & 5.55 & 1.12 & 1.12 & 6.22 & 6.22 & 1.54 & 1.54 & 9.59 & 9.5 \\
\hline 1962 & 5.89 & 5.89 & 1.16 & 1.16 & 6.84 & 6.84 & 1.55 & 1.55 & 10.59 & \\
\hline 1963 & 6.05 & 6.05 & 1.17 & 1.17 & 7.11 & 7.11 & 1.56 & 1.56 & 11.10 & \\
\hline 1964 & 6.47 & 6.47 & 1.19 & 1.19 & 7.67 & 7.67 & 1.58 & 1.58 & 12.11 & 12. \\
\hline 1965 & 6.71 & 6.71 & 1.18 & 1.18 & 7.95 & 7.95 & 1.63 & 1.63 & 12.99 & \\
\hline 1966 & 6.64 & 6.64 & 1.18 & 1.18 & 7.83 & 7.83 & 1.69 & 1.69 & 13.24 & 13. \\
\hline 1967 & 5.96 & 5.96 & 1.13 & 1.13 & 6.75 & 6.75 & 1.74 & 1.74 & 11.76 & \\
\hline 1968 & 5.97 & 5.97 & 1.12 & 1.12 & 6.70 & 6.70 & 1.82 & 1.82 & 12.19 & \\
\hline 1969 & 5.55 & 5.55 & 1.10 & 1.10 & 6.15 & 6.15 & 1.87 & 1.87 & 11.49 & 11. \\
\hline 1970 & 4.67 & 4.67 & 1.07 & 1.07 & 5.01 & 5.01 & 1.90 & 1.90 & 9.54 & 9.5 \\
\hline 1971 & 4.66 & 4.66 & 1.10 & 1.10 & 5.14 & 5.14 & 1.90 & 1.90 & 9.76 & 9.76 \\
\hline 1972 & 4.99 & 4.99 & 1.15 & 1.15 & 5.73 & 5.73 & 1.90 & 1.90 & 10.90 & 10.9 \\
\hline 1973 & 5.80 & 5.80 & 1.20 & 1.20 & 6.96 & 6.96 & 1.96 & 1.96 & 13.68 & \\
\hline 1974 & 5.23 & 5.23 & 1.33 & 1.33 & 6.94 & 6.94 & 2.03 & 2.03 & 14.09 & \\
\hline 1975 & 4.37 & 4.37 & 1.29 & 1.29 & 5.66 & 5.66 & 2.02 & 2.02 & 11.42 & \\
\hline 1976 & 5.06 & 5.06 & 1.32 & 1.32 & 6.70 & 6.70 & 2.01 & 2.01 & 13.49 & 13. \\
\hline 1977 & 4.84 & 4.84 & 1.35 & 1.35 & 6.54 & 6.54 & 2.04 & 2.04 & 13.31 & \\
\hline 1978 & 5.05 & 5.05 & 1.36 & 1.36 & 6.85 & 6.85 & 2.08 & 2.08 & 14.22 & 14. \\
\hline 1979 & 5.41 & 5.41 & 1.40 & 1.40 & 7.55 & 7.55 & 2.14 & 2.14 & 16.12 & 16. \\
\hline 1980 & 4.92 & 4.92 & 1.40 & 1.40 & 6.91 & 6.91 & 2.17 & 2.17 & 15.00 & \\
\hline 1981 & 4.75 & 4.75 & 1.38 & 1.38 & 6.57 & 6.57 & 2.18 & 2.18 & 14.34 & \\
\hline 1982 & 3.67 & 3.67 & 1.28 & 1.28 & 4.69 & 4.69 & 2.18 & 2.18 & 10.23 & \\
\hline 1983 & 4.08 & 4.08 & 1.25 & 1.25 & 5.08 & 5.08 & 2.14 & 2.14 & 10.89 & 10. \\
\hline 1984 & 4.91 & 4.91 & 1.25 & 1.25 & 6.13 & 6.13 & 2.21 & 2.21 & 13.57 & 13. \\
\hline 1985 & 3.85 & 3.85 & 1.19 & 1.19 & 4.58 & 4.58 & 2.27 & 2.27 & 10.40 & 10. \\
\hline 1986 & 3.77 & 3.77 & 1.10 & 1.10 & 4.16 & 4.16 & 2.42 & 2.42 & 10.07 & \\
\hline 1987 & 4.82 & 4.82 & 1.10 & 1.10 & 5.3 & 5.31 & 2.49 & 2.49 & 13.22 & \\
\hline 1988 & 5.68 & 5.68 & 0.97 & 0.97 & 5.5 & 5.5 & 2.98 & 2.98 & 16.47 & \\
\hline 1989 & 4.88 & 4.88 & 0.95 & 0.95 & 4.61 & 4.61 & 3.18 & 3.18 & 14.68 & 14. \\
\hline 1990 & 4.05 & 4.05 & 0.95 & 0.95 & 3.86 & 3.86 & 3.25 & 3.25 & 12.54 & 12. \\
\hline 199 & 2.44 & 2.44 & 0.92 & 0.92 & 2.24 & 2.24 & 3.22 & 3.22 & 7.22 & 7.2 \\
\hline 1992 & 2.98 & 2.98 & 0.93 & 0.93 & 2.76 & 2.76 & 3.61 & 3.61 & 9.97 & 9.9 \\
\hline 1993 & 3.45 & 3.45 & 0.89 & 0.89 & 3.05 & 3.05 & 3.69 & 3.69 & 11.26 & \\
\hline 199 & 5.0 & 4.7 & 0.45 & 0.91 & 2.2 & 4.3 & 6.40 & 3.57 & 14.41 & \\
\hline & 5.20 & 4.70 & 0.45 & 0.94 & 2.3 & 4.43 & 6.29 & 3.48 & 14.62 & \\
\hline 199 & 5.93 & 5.42 & 0.44 & 0.91 & 2.6 & 4.9 & 6.17 & 3.86 & 16.07 & 18. \\
\hline 1997 & & 5.22 & 0.43 & 0.94 & 2.52 & 4.88 & 6.20 & 3.35 & 15.62 & \\
\hline 1998 & 5.82 & 5.30 & 0.40 & 0.87 & 2.34 & 4.63 & 6.39 & 3.50 & 14.96 & 16 \\
\hline & 6.48 & 5.71 & 0.39 & 0.90 & 2.56 & 5.12 & & 3.30 & 16.36 & \\
\hline 2000 & 6.18 & 5.55 & 0.41 & 0.85 & 2.51 & 4.74 & 6.09 & 3.32 & 15.28 & 15. \\
\hline 2001 & 2.78 & 2.80 & 0.39 & 0.86 & 1.08 & 2.41 & 6.11 & 3.17 & 6.61 & 7.6 \\
\hline
\end{tabular}

Now things begin to make a little more sense. While the last 8 years have brought some changes (total asset turnover is lower than ever, leverage is coming back to earth after the wild rise beginning in 1988) things are a little more like we would expect based on pre-1994 data. Let's look at the data in graphical form. 
GRAPH 1--FORTUNE 500 Return on Sales

F500 ROS

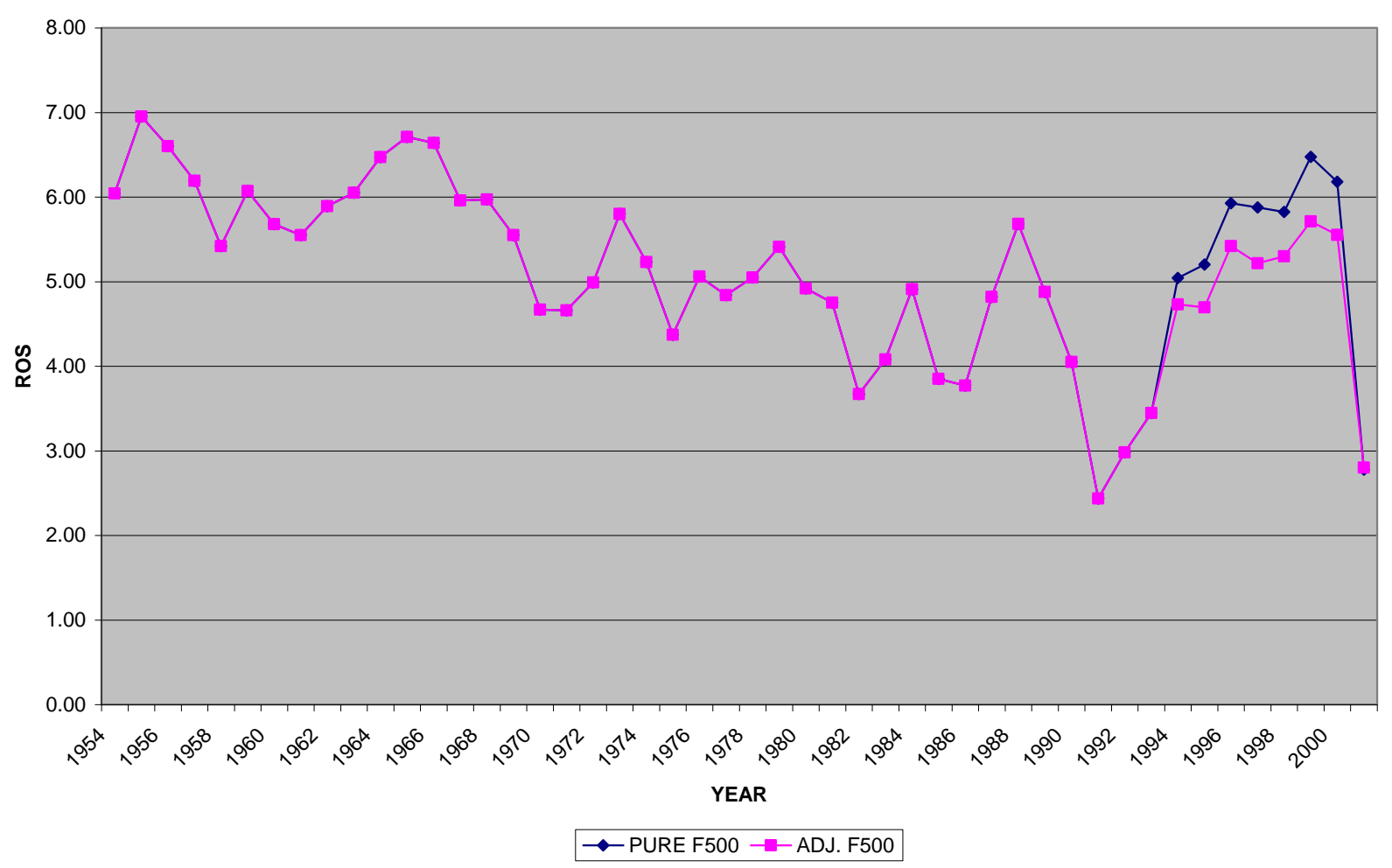

For this ratio the two lines are not that far apart. The "pure" line is slightly higher because--year in/year out-- financial institutions have a "slightly" higher ROS than other firms. The long-tern downward trend is also obvious as well as the significant drop in 2001. 
GRAPH 2--FORTUNE 500 Total Asset Turnover

F500 S/A

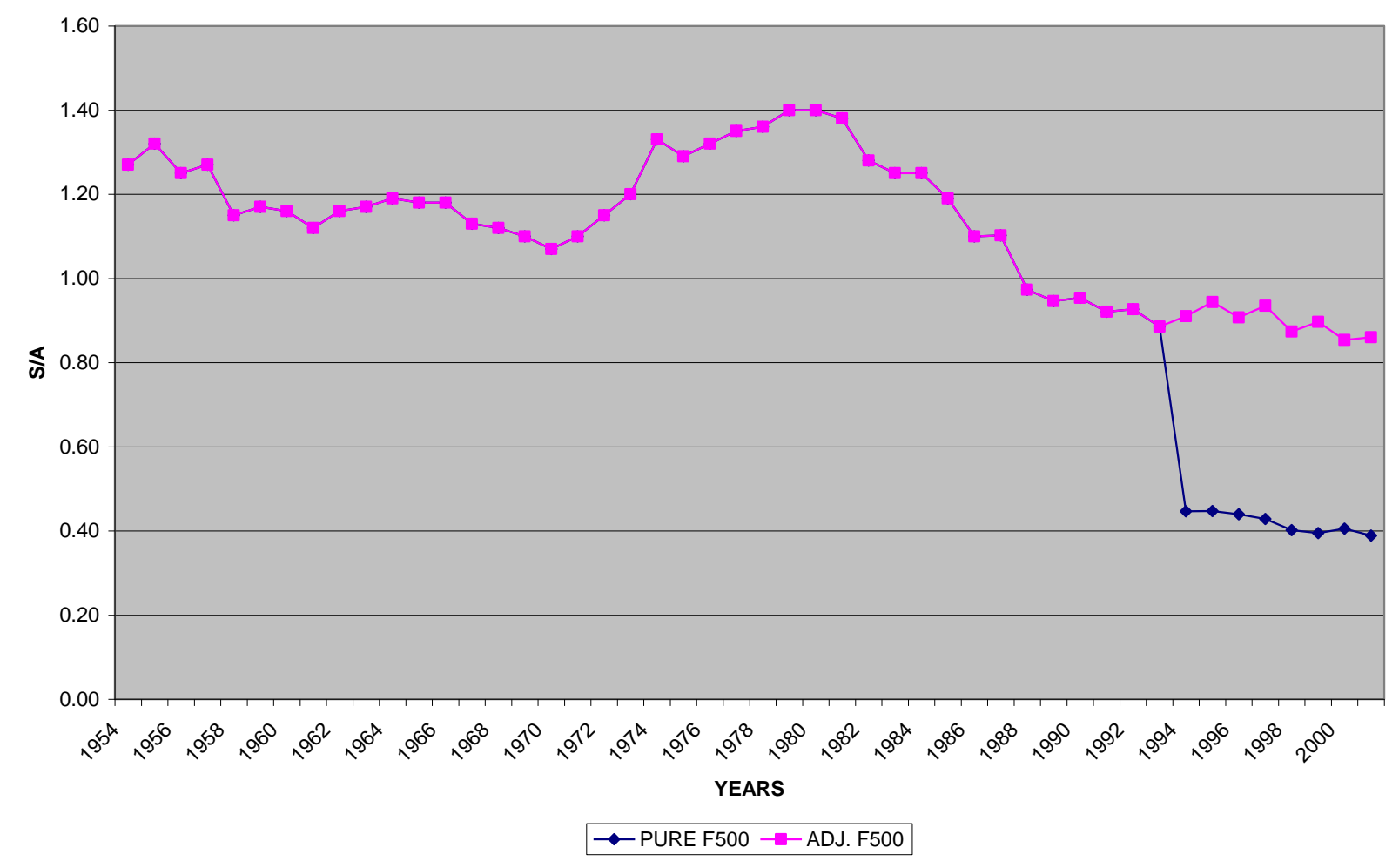

Here is where we have a significant difference between the two lines. The "pure" line is less than half the "adjusted" line. This is because most financial institutions have S/A ratios of less than 0.10. Aside from the pure/adjusted difference, the sharp downward trend beginning in 1988 should be noted. This is when the Financial Accounting Standards Board implemented the rule that all majority owned subsidiaries had to be consolidated (e.g., General Motors had to include GMAC in their financial statements). 


\section{GRAPH 3--FORTUNE 500 Return on Assets}

F500 ROA

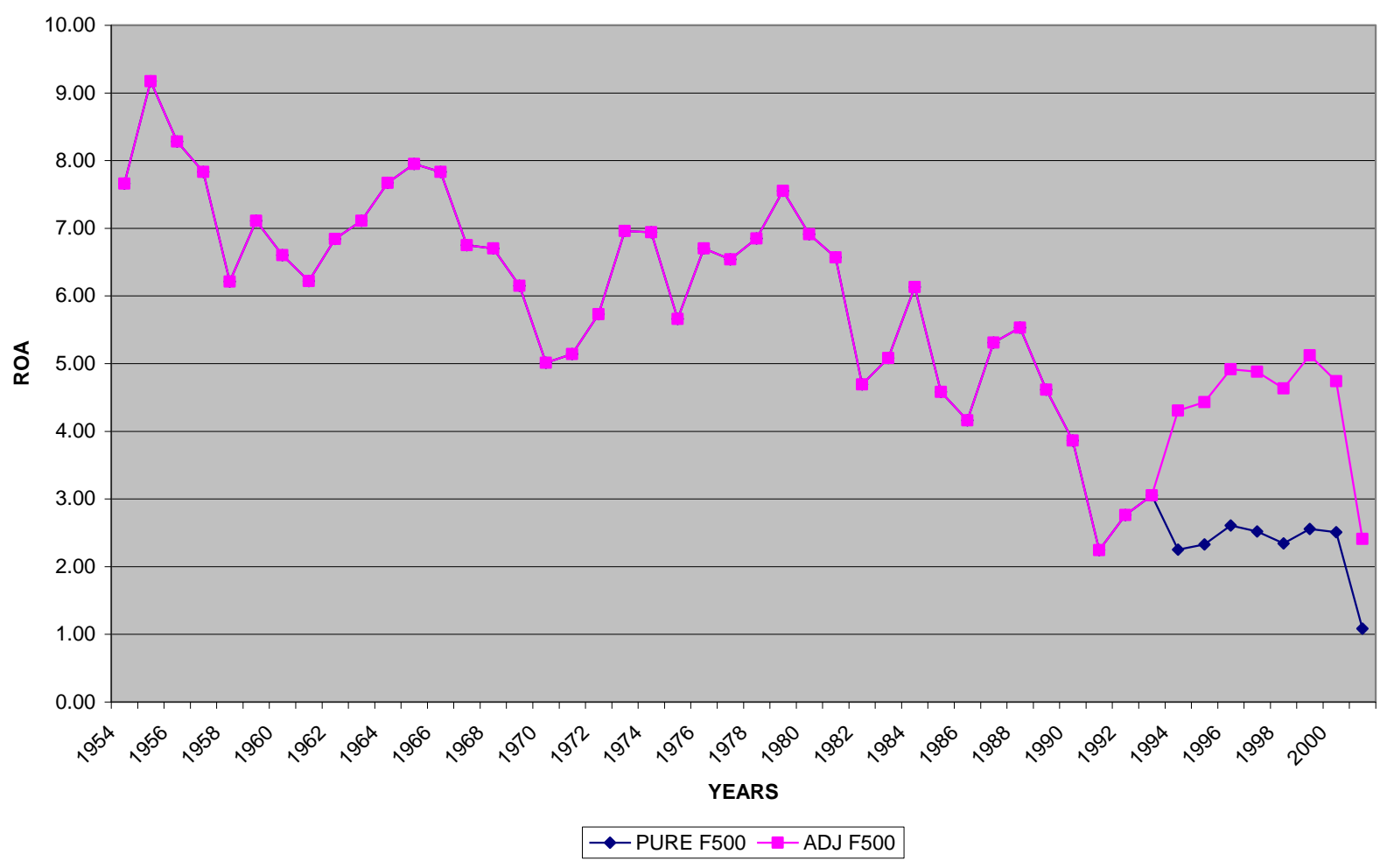

Again, we have a significant difference, with the "pure" line lower. The slightly higher "pure" ROS does not compensate for the much lower "pure" S/A (ROA being the product of the two). Here too, we have the disturbing long-term downward trend, even considering the relative impressive performance of the 1990's. It appears reasonable to assume that we will never see averages of 7 or higher for this ratio again. 
GRAPH 4--FORTUNE 500 Leverage

\section{LEVERAGE}

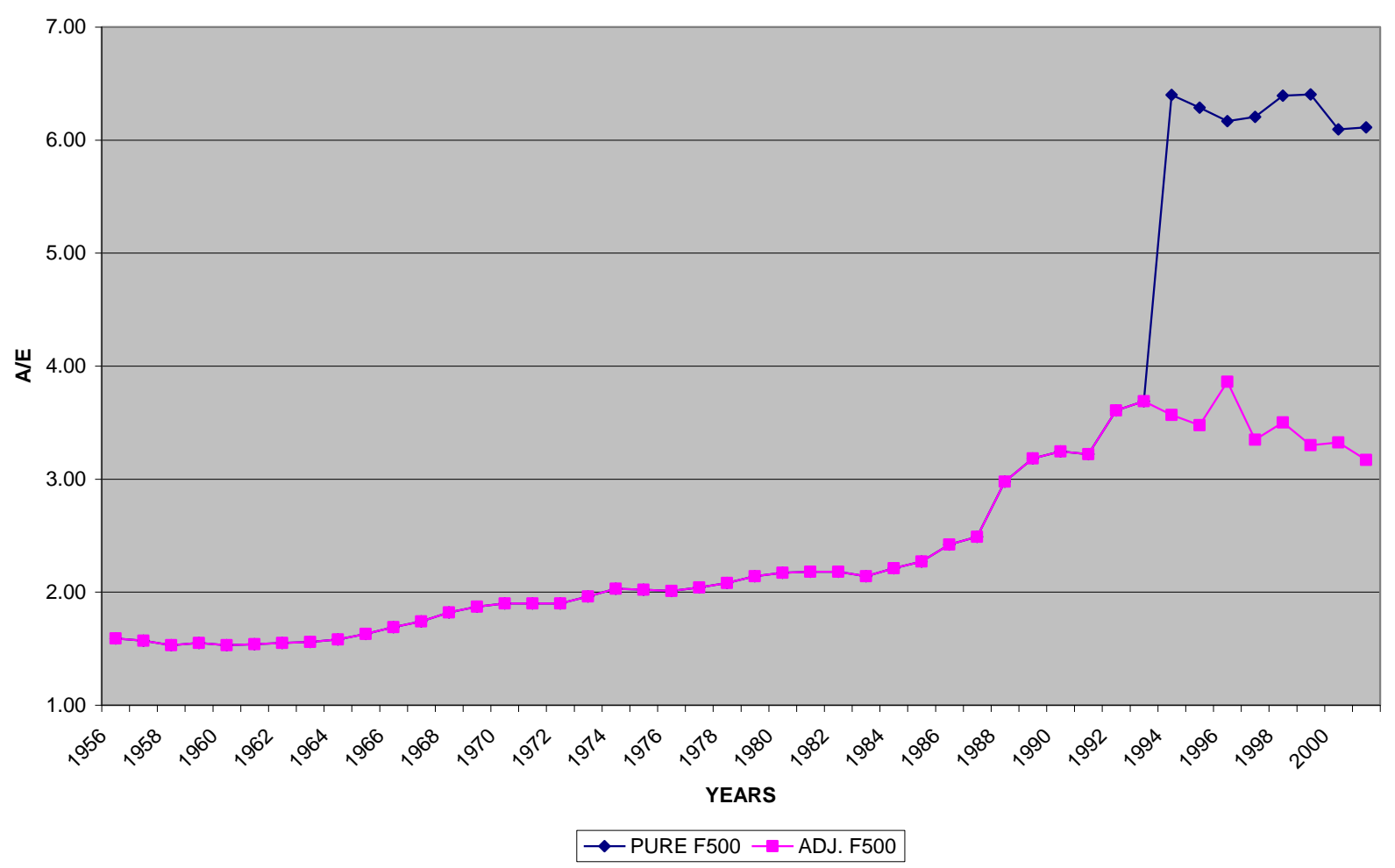

Arguably, this is the most significant difference of all. With many financial institutions running leverage factors in the middle teens it is easy to see why the "pure" line is so much higher. As was the case with Total Asset Turnover, the 1988 decision by the Financial Accounting Standards Board had an impact on the FORTUNE 500 averages, but this time in the opposite direction (i.e., mixing GMAC with General Motors lowers it's S/A and raises it's $\mathrm{A} / \mathrm{E}$ ). The $\mathrm{X} / \mathrm{Y}$ intercept of this graph is placed at 1.0 since that is the lowest that this ratio can be. 


\section{GRAPH 5--FORTUNE 500 Return on Equity}

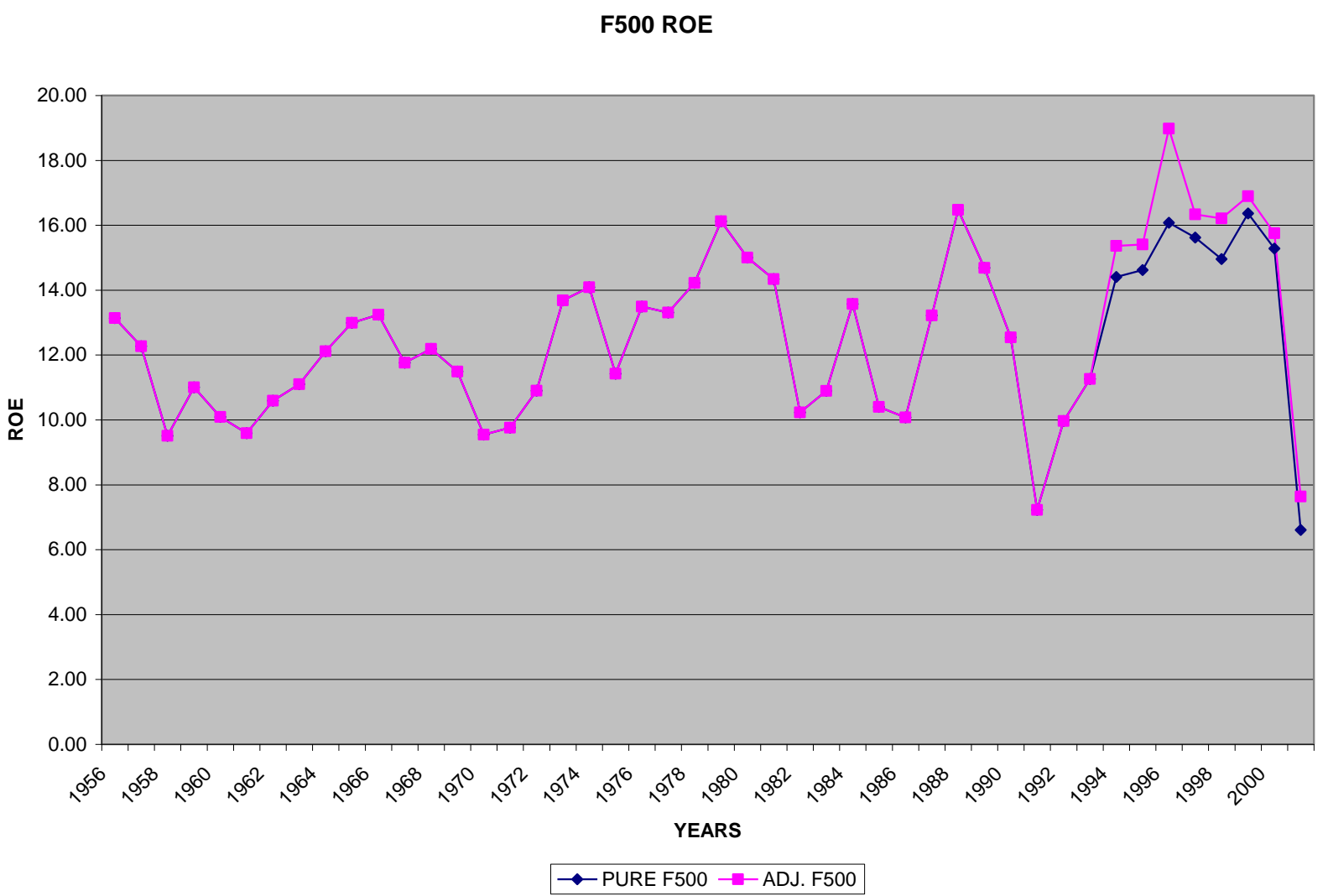

In my opinion, this is the most interesting finding of this study. Return on Equity--arguably the most important ratio that we can use to measure corporate financial success--is probably not different enough in the "pure" form as compared to the "adjusted" form to be worth being concerned about. The two lines are much closer together than any of the other four "Dupont" measures.

\subsection{Conclusions}

1) If you want to have your students do a case study of a financial institution, they need to compare the financial ratios to other financial institutions.

2) If you want to have your students do a case study of anything but a financial institution they need to use the "adjusted" FORTUNE 500 "Dupont" ratios for comparison.

3) The "adjusted" FORTUNE 500 "Dupont" comparison ratios can be computed by removing all of the financial institutions from the"pure" FORTUNE 500. This will generally result in a FORTUNE 500 that is a FORTUNE 415-425, but that is a valid part of the pre 1994 data set. 


\section{Reference}

1. Thompson, Arthur A., and A. J. Strickland III, Strategic Management: Concepts and Cases, Thirteenth Edition, McGraw-Hill/Irwin, 2003.

J. Deile

Stetson School of Business \& Economics, Mercer University

Macon, GA 31207

DEILE_AJ@MERCER.EDU , 478-301-2843 (office)

Notes 